\title{
Sistem Deteksi Bentuk Kecacatan Benda Padat Menggunakan Teknik Variasi Sudut Ultrasonik
}

\author{
Taufiq Nur Syahril Sidiq*1, Abdul Rouf ${ }^{2}$,Tri Wahyu Supardi ${ }^{3}$ \\ ${ }^{1}$ Prodi Elektronika dan Instrumentasi Jurusan Ilmu Komputer dan Elektronika, FMIPA UGM \\ ${ }^{2,3}$ Jurusan Ilmu Komputer dan Elektronika, FMIPA UGM \\ e-mail: *1'taufiqnursyahrilsidiq@gmail.com, ${ }^{2}$ rouf@ugm.ac.id, ${ }^{3}$ twsupardi@ugm.ac.id
}

\begin{abstract}
Abstrak
Proses pembuatan material benda padat sering terjadi masalah berupa kecacatan yang timbul di dalam benda padat tersebut. Penelitian ini bertujuan untuk membuat suatu sistem untuk mendeteksi bentuk kecacatan di dalam benda padat menggunakan gelombang ultrasonik. Komponen yang digunakan pada sistem adalah generator fungsi, penguat, sensor ultrasonik, oscilloscope dan benda padat uji berbentuk silinder. Metode yang digunakan adalah metode pantul gelombang ultrasonik. Gelombang ultrasonik dari transmitter dipancarkan ke benda padat dan receiver akan membaca gelombang hasil pantulan yang terjadi karena perbedaan medium benda. Oscilloscope akan membaca gelombang ultrasonik hasil pantulan. Pembacaan ini dilakukan untuk dapat menentukan bentuk dari kecacatan benda padat berbentuk silinder.

Uji coba sistem dengan cara unit transmitter memancarkan gelombang ultrasonik ke benda padat. Benda padat diputar atau digerakkan setiap kelipatan $20^{\circ}$ dari $0-180^{\circ}$ untuk mendapatkan variasi sudut pantul. Hasil yang didapat bahwa gelombang ultrasonik sebesar 40 $\mathrm{KHz}$ dapat mendeteksi bentuk kecacatan benda padat. Setiap bentuk kecacatan pada benda padat tersebut mempunyai pola gelombang yang berbeda. Pola gelombang konstan dengan amplitudo kecil merupakan benda padat berbentuk silinder tanpa kecacatan, pola gelombang konstan dengan amplitudo lebih besar merupakan benda padat silinder dengan kecacatan yang juga berbentuk silinder dan pola gelombang maupun amplitudo berbeda pada setiap variasi sudut merupakan benda padat silinder dengan kecacatan berbentuk kubus.
\end{abstract}

Kata kunci-ultrasonik, generator fungsi, oscilloscope, transmitter, receiver, kecacatan benda padat

\section{Abstract}

Making solid material frequent problems of internal defect. This research intends to make a system to detect the form of defect in solid materials using ultrasonic waves. Components that was used in the system is a generator function, an op-amp, ultrasonic sensor, oscilloscope and cylindrical solid material The method that used is reflected method of ultrasonic. Ultrasonic waves emitted from the transmitter to a solid material and the receiver will read a results of the reflection that occurs due to differences in medium objects. Oscilloscope will read of ultrasonic. Recitation will be done to determine the form of any cylindrical solid object.

The trial system by a unit transmitter emits ultrasonic waves on the side solid material. A solid body rotated every multiple $20^{\circ}$ of $0-180^{\circ}$ to get an angle variations. The result obtained that waves as $40 \mathrm{khz}$ can detect the form of solid material defect. The form of defect in a solid material has different wave pattern. Constant wave patterns with small amplitudo is a cylindrical material without defect, constant wave patterns with more much amplitudo is cylindrical material with cylindrical defect also and wave patterns whose amplitudo is different in any variation angle is cylindrical solid with cubicaly defect.

Keywords - ultrasonic, generator function, oscilloscope, transmitter, receiver, defect of solid materials 


\section{PENDAHULUAN}

$\mathrm{D}^{\mathrm{s}}$ alam dunia industri pembuatan peralatan dengan material benda padat baik secara otomatis menggunakan mesin maupun yang masih menggunakan tenaga manusia, tidak bisa terlepas dari masalah kecacatan fisik atau kerusakan yang terjadi di dalam benda tersebut. Kecacatan fisik yang terjadi dalam skala yang besar akan berdampak terhadap kerugian finansial bahkan bisa membuat bahaya bagi keselamatan pekerja ataupun pengguna benda produksi. Kecacatan fisik yang berada di dalam benda padat tentu saja tidak dapat diketahui dari penglihatan secara langsung sehingga perlu dilakukannya sebuah inspeksi dari suatu benda untuk melihat ada atau tidaknya kecacatan yang terjadi di dalam benda padat [1]. Inspeksi yang dilakukan di dunia industri tanpa merusak benda padat yang di inspeksi biasa disebut dengan Non-Destructive Test.

Non-Destructive Test (NDT) didefinisikan sebagai suatu evaluasi fisik dari suatu objek benda padat yang diuji. NDT digunakan terutama dalam dunia industri untuk mendeteksi kecacatan, retak dan rongga dalam bahan yang digunakan dalam berbagai struktur dengan material yang berbeda-beda jenisnya [2]. Dalam NDT terdapat berbagai macam metode pengujian seperti liquid penetrant test, magnetic particle inspection, eddy current test, radiographic inspection, dan ultrasonic inspection. Setiap metode NDT mempunyai kelebihan dan kekurangan masing-masing. Beberapa metode yang tersedia hanya dapat dilakukan pengujian pada permukaan benda padat seperti liquid penetrant test dan magnetic particle inspection. Metode eddy current test benda padat biasa digunakan untuk inspeksi namun terbatas pada jenis material yaitu yang bersifat konduktif. Pengujian menggunakan radiographic dapat digunakan untuk inspeksi hingga internal benda tetapi mempunyai efek radiasi sinar $\gamma$ (gamma) yang berbahaya bagi manusia. Dalam NDT, pengujian menggunakan gelombang ultrasonik lebih populer digunakan karena pengujian tersebut dirasa aman untuk digunakan pada berbagai jenis material benda dan dapat menjangkau internal benda yang di uji [3].

Dengan kemajuan teknologi yang begitu pesat, perkembangan pembuatan produk menggunakan material benda padat dalam dunia industri telah banyak menggunakan gelombang ultrasonik yang menjadikannya sebagai pilihan utama [4]. Setiap barang yang telah selesai diproduksi akan dideteksi ada atau tidaknya kecacatan fisik di dalamnya. Di dalam proses produksi benda padat, sering terjadi kecacatan dengan bentuk kecacatan yang sama pada setiap benda dalam satu masa produksi. Bentuk kecacatan yang terjadi diakibatkan dari proses produksi yang tidak sempurna yang dilakukan secara terus-menerus. Adanya kecacatan di dalam benda padat perlu diketahui bentuk dari kecacatan benda padat tersebut agar memudahkan proses identifikasi masalah dari proses produksi dan mengurangi resiko terjadinya kecacatan yang sama pada produksi selanjutnya. Gelombang ultrasonik akan dipancarkan pada permukaan benda padat yang selanjutnya sensor ultrasonik akan mendapatkan pantulan kembali mulai dari pantulan permukaan benda hingga sisi sebaliknya dari benda padat tersebut untuk mengetahui karakteristik gelombang pantul yang dihasilkan pada bentuk tertentu dari kecacatan benda padat.

\section{METODE PENELITIAN}

\subsection{Analisis Sistem}

Analisis pada sistem deteksi bentuk kecacatan menggunakan gelombang ultrasonik terdiri dari bahan, peralatan, pengujian benda padat uji, dan pengambilan data variasi sudut benda padat uji.

\subsubsection{Bahan} silinder.

Benda padat uji dibuat dari cetakan antara semen, pasir halus dan air yang berbentuk

IJEIS Vol. 6, No. 1, April 2016 : $69-80$ 


\subsubsection{Peralatan}

a. Sensor ultrasonik $40 \mathrm{KHz}$

b. Amplifier LM386

c. Transformator step up

d. SRF 04

e. Oscilloscope digital Protek 3025

f. Audio Function Generator (AFG) GW Instek GFG-8020H

\subsubsection{Prosedur dan pengumpulan data}

Dalam proses pengujian, benda padat uji diletakkan di depan sensor ultrasonik yang berfungsi sebagai transmitter dan receiver. Sisi benda padat uji yang digunakan merupakan sisi selimut dari benda tersebut. Sisi selimut merupakan sisi luar dari benda yang apabila tampak dari atas berbentuk lingkaran sehingga dapat digunakan untuk variasi sudut saat pengujian. Transmiter akan memancarkan gelombang ultrasonik yang dihasilkan unit transmitter sebesar $40 \mathrm{KHz}$ yang sudah dikuatkan dayanya. Kemudian gelombang pantulan dari benda padat uji akan diterima oleh sensor ultrasonik sebagai receiver dan dikuatkan kembali dayanya agar dapat dibaca oleh oscilloscope.

Benda padat uji berbentuk silinder dengan diameter $14 \mathrm{~cm}$ sehingga permukaan benda mempunyai keliling sebesar $44 \mathrm{~cm}$. Besaran variasi sensor yang digunakan pada penelitian ini dapat dihitung dari besar panjang sensor. Sensor dengan panjang $3,5 \mathrm{~cm}$ diletakkan di depan benda padat uji dan dari kondisi tersebut dapat diketahui panjang busur dihadapan sensor sebesar $2,5 \mathrm{~cm}$. Untuk mendapatkan nilai sudut maka digunakan perhitungan berikut.

$$
\begin{aligned}
\text { Panjang busur } & =\frac{\theta}{360} \cdot 2 \cdot \pi \cdot \mathrm{r} \\
2,50 & =\frac{6}{960} \cdot 2 \cdot \pi \cdot 7 \\
\theta & =\frac{250 \times 160}{43,98} \\
\theta & =20,46^{\circ}
\end{aligned}
$$

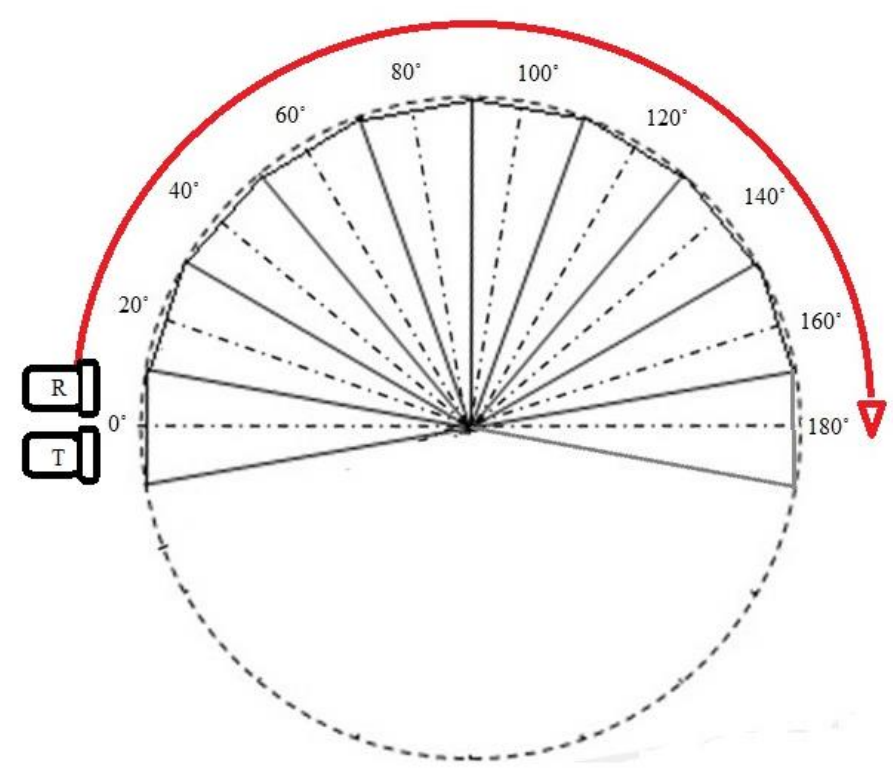

Gambar 1 Metode yang digunakan dalam pengujian benda padat

Teknik variasi sudut yang digunakan pada penelitian ini ditunjukkan pada Gambar 1 . Besaran variasi sudut yang digunakan pada penelitian ini berdasarkan perhitungan sudut dari panjang busur yang dapat dijangkau sensor dibulatkan menjadi $20^{\circ}$. Benda padat uji pada sisi dari $0-180^{\circ}$ dibagi menjadi sepuluh bagian. Sepuluh bagian ini mengikuti variasi sudut dimana 
sensor ultrasonik akan dipancarkan ke benda padat uji setiap kelipatan $20^{\circ}$. Oleh karena itu, benda padat uji dapat digambarkan sebagai segi delapan belas dimana setiap sisi segi dilakukan pengujian deteksi bentuk kecacatan. Dari delapan belas segi yang digambarkan pada pengujian ini, hanya dilakukan pengujian pada sepuluh segi yang mewakili sepuluh variasi sudut. Sehingga pada pengujian ini terdapat sepuluh variasi gelombang pantul yang dibaca oleh receiver. Untuk setiap variasi sudut sensor ultrasonik yang dipancarkan pengujian dilakukan sebanyak tiga kali pada setiap bagian.

Pengambilan data setiap variasi sudut benda padat uji menggunakan oscilloscope digital didapat dari hasil gelombang pantul benda padat. Untuk dapat dianalisis bentuk kecacatan di dalam benda padat, pada tampilan oscilloscope digital diharapkan akan muncul suatu gelombang yang sama dengan gelombang yang dipancarkan oleh transmitter yaitu berbentuk sinus. Gelombang tersebut kemudian akan dilihat besaran amplitudo untuk mengetahui tegangan yang dihasilkan gelombang. Gelombang berupa sinusoidal akan dianalisis untuk mengetahui bentuk kecacatannya seperti yang ditunjukkan pada Gambar 2.

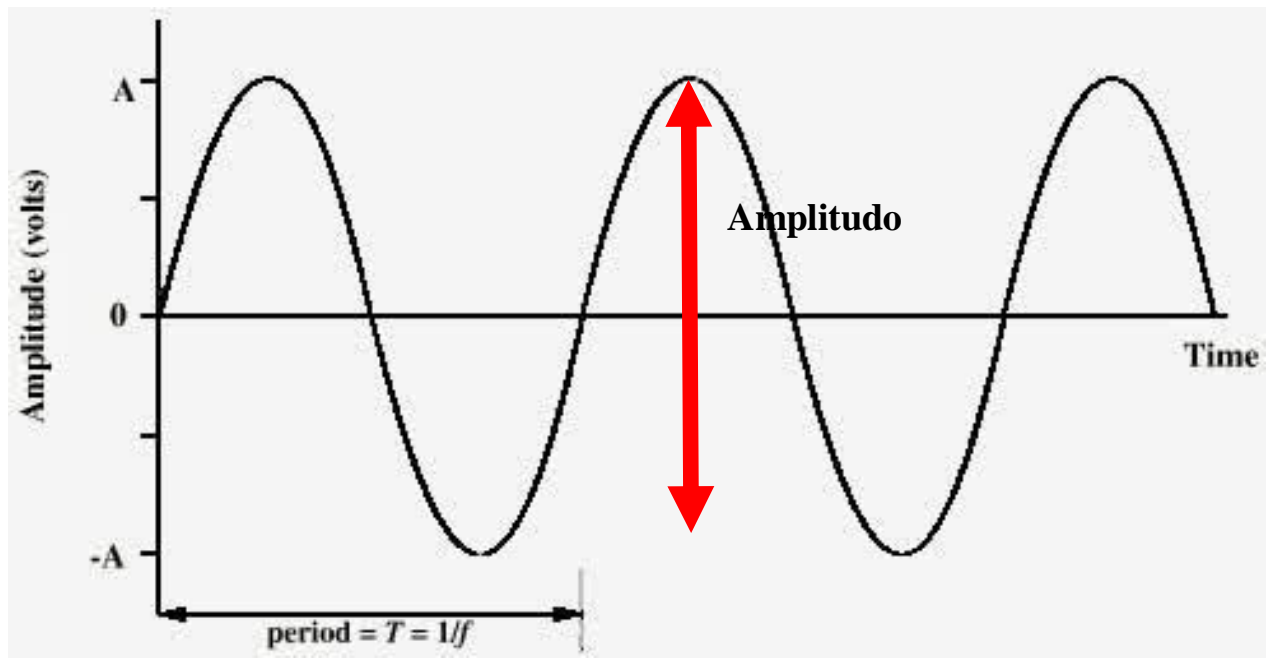

Gambar 2 Gelombang sinusoidal

Gelombang sinusoidal yang didapat akan di hitung nilai amplitudo untuk setiap pengujian. Nilai amplitudo yang dihitung dalam oscilloscope berupa satuan div yang kemudian dikalikan dengan nilai skala volt/div pada oscilloscope sehingga didapat sebuah nilai tegangan dalam satuan Volt. Nilai tegangan gelombang tersebut akan digunakan untuk mengetahu pola dari bentuk kecacatan di dalam benda padat.

\section{2 Perancangan Sistem}

Sistem yang akan dirancang untuk penelitian ini merupakan suatu sistem yang dapat mendeteksi bentuk kecacatan pada benda padat dengan memanfaatkan pancaran dan pantulan gelombang ultrasonik pada variasi sudut benda padat tersebut. Bagian transmitter merupakan bagian awal sistem deteksi benda padat dimana gelombang ultrasonik dipancarkan oleh transmitter ultrasonik. Transmitter mendapatkan nilai frekuensi dari pengaturan generator fungsi (AFG) dan telah dikuatkan dayanya oleh rangkaian penguat. Pancaran gelombang ultrasonik diarahkan ke benda padat yang akan diuji. Gelombang ultrasonik tersebut sebagian akan ada yang terserap ke benda padat dan sebagian lagi ada yang memantul kembali pada setiap perbedaan medium benda yang ditemuinya. Setiap pantulan yang didapat akan diterima oleh receiver ultrasonik pada bagian unit receiver. Benda padat yang berbentuk silinder akan diputar untuk mendapatkan variasi sudut pendeteksian benda padat. Hal ini dilakukan untuk memperoleh hasil pembacaan kecacatan yang berbeda pada setiap variasi sudut. Pada unit receiver, gelombang ultrasonik yang diterima akan dikuatkan dayanya agar gelombangnya dapat terbaca di oscilloscope digital. Hal tersebut ditunjukkan pada Gambar 3. 


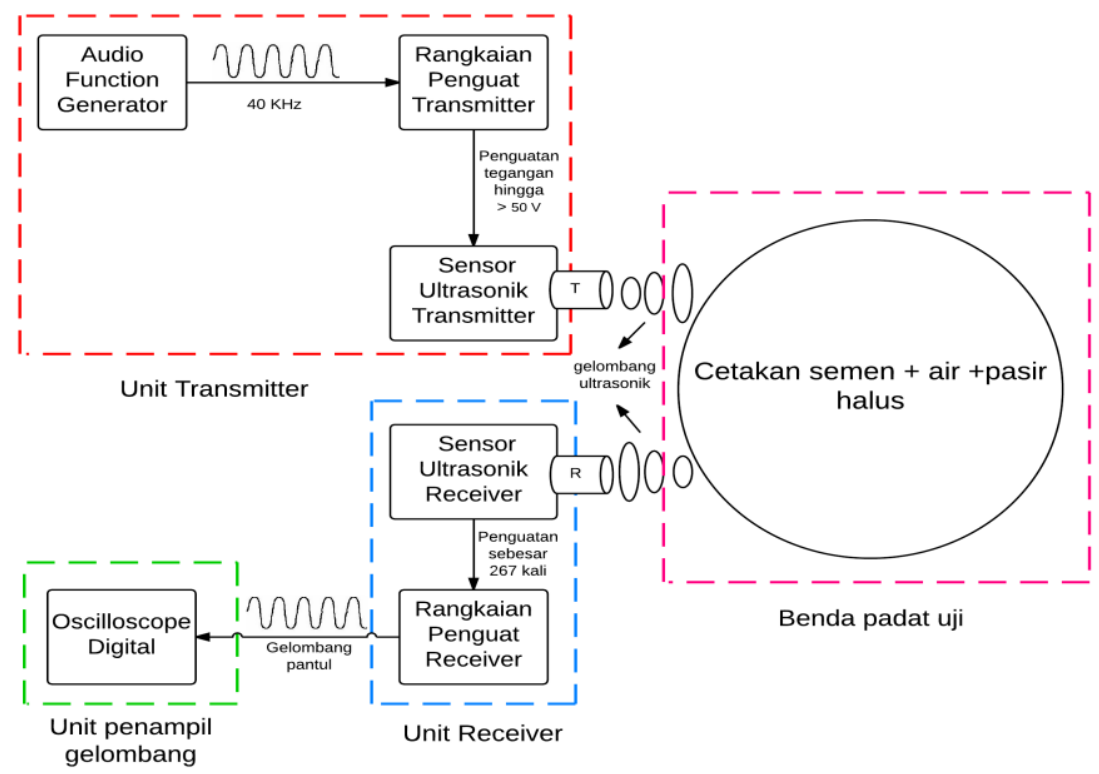

Gambar 3 Blok diagram rancangan sistem e-nose secara keseluruhan

\subsection{Rancangan Perangkat Keras}

Perangkat keras yang digunakan dalam sistem ini berupa rangkaian penguat, sensor ultrasonik, Generator fungsi (AFG), dan oscilloscope. Sensor ultrasonik yang digunakan berupa dua buah probe yang berfungsi sebagai transmitter dan receiver.

\subsubsection{Rancangan unit transmitter}

Transmitter dari sensor ultrasonik ini mendapatkan frekuensi dari AFG yang telah diatur nilai frekuensinya. AFG memberikan gelombang sinus sebesar $40 \mathrm{KHz}$ yang kemudian akan masuk ke rangkaian penguat. Rangkaian penguat sebelumnya mendapatkan sumber listrik dari catu daya dengan tegangan keluaran sebesar $12 \mathrm{~V}$ DC. Rangkaian penguat tersebut merupakan rangkaian amplifier LM386 yang dapat menguatkan daya gelombang. Selain itu, pengaturan variabel resistor juga diperlukan untuk memperoleh gelombang sinus yang baik. Pengaturan tersebut dilakukan dengan cara memutar variable resistor untuk menambah atau mengurangi nilai resistansi masukan. Gelombang yang telah dikuatkan tersebut akan dipancarkan oleh transmitter ultrasonik ke arah benda padat yang akan dideteksi. Perancangan dari unit transmitter ditunjukkan pada Gambar 4.

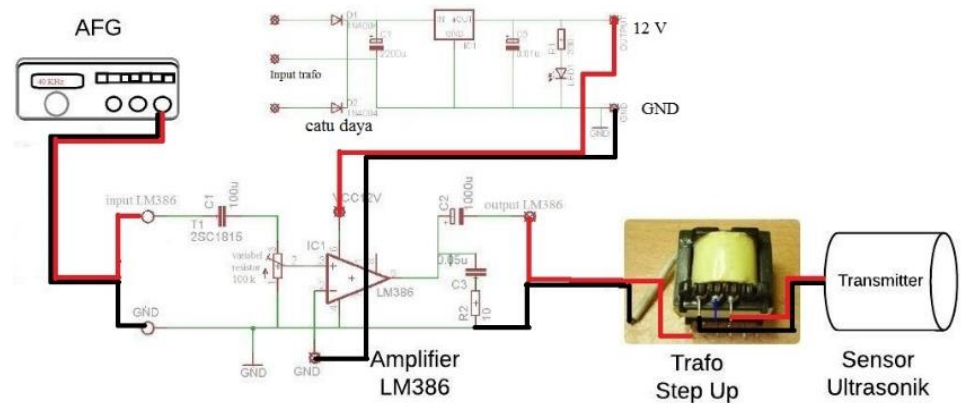

Gambar 4 Rancangan unit transmitter

\subsubsection{Rancangan unit receiver dan oscilloscope}

Receiver ultrasonik akan menerima gelombang ultrasonik tersebut dari pantulan benda padat. Gelombang pantulan akan lebih mudah dibaca pada oscilloscope apabila telah dikuatkan kembali. Pada unit receiver untuk memperkuat daya dari gelombang yang dibaca oleh receiver, digunakan penguat LMC6032. LMC6032 pada penelitian ini diambil dari modul SRF 04 
(Ultrasonic Range Finder). Sumber listrik yang dibutuhkan untuk modul SRF 04 adalah 5 V DC. Gelombang yang diterima oleh receiver dan telah dikuatkan akan dibaca oleh oscilloscope. Perancangan dari unit receiver ditunjukkan pada Gambar 5.

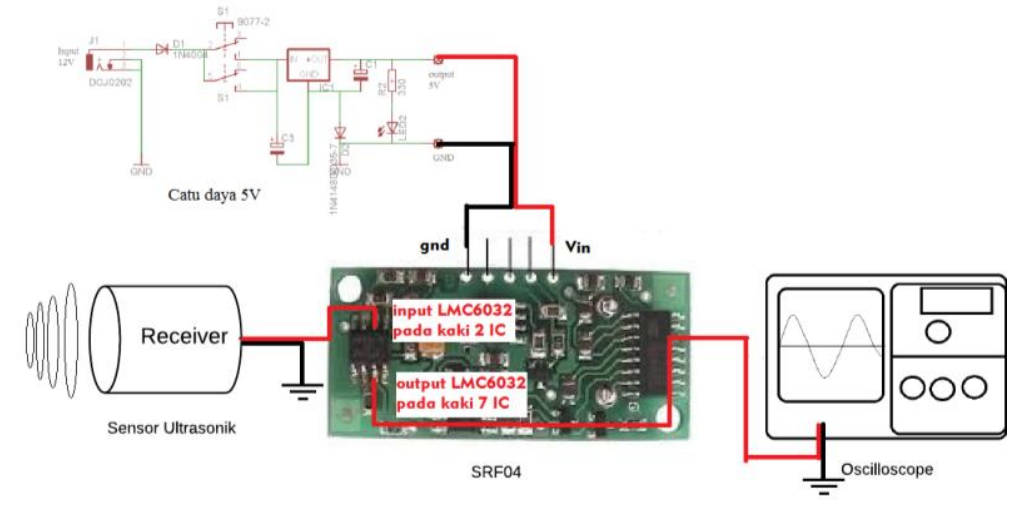

Gambar 5 Rancangan unit receiver dan oscilloscope

\section{$2.4 \quad$ Rancangan Benda Padat Uji}

Pada penelitian ini digunakan benda padat uji yang ditentukan sendiri bentuk benda serta bentuk kecacatan di dalam benda padat tersebut. Tabel 1 merupakan rancangan dari pembuatan benda padat uji. Benda padat uji dibuat dari cetakan antara semen, pasir halus dan air. Benda padat uji yang digunakan pada penelitian ini terdapat tiga variasi benda dengan bentuk yang sama yaitu berbentuk silinder. Setiap variasi benda mempunyai bentuk kecacatan yang berbeda-beda. Benda padat yang pertama merupakan benda padat berbentuk silinder utuh. Benda padat yang kedua berupa benda padat silinder dengan kecacatan berbentuk lubang silinder dengan diameter lubang sebesar $8 \mathrm{~cm}$. Kemudian benda padat yang ketiga merupakan benda padat silinder dengan kecacatan berbentuk lubang kubus dengan panjang semua sisinya sebesar $7 \mathrm{~cm}$. Dari variasi benda padat yang dibuat berbentuk silinder, sistem deteksi dapat menggunakan metode pantul ultrasonik dengan cara memutar benda padat uji. Hal tersebut bertujuan untuk mendapatkan nilai amplitdo gelombang pada setiap sudut yang divariasikan setiap $20^{\circ}$.

\section{Tabel 1 Rancangan benda padat uji}

\begin{tabular}{|c|c|c|c|c|c|}
\hline $\begin{array}{l}\text { No } \\
\text {. }\end{array}$ & Objek pengujian & $\begin{array}{l}\text { Ukuran } \\
\text { benda }\end{array}$ & $\begin{array}{l}\text { Bentuk } \\
\text { kecacatan }\end{array}$ & $\begin{array}{l}\text { Keterangan } \\
\text { kecacatan }\end{array}$ & Gambar benda \\
\hline 1 & $\begin{array}{l}\text { Benda padat uji } \\
\text { I }\end{array}$ & $\begin{array}{l}\text { Diameter } \\
=14 \\
\text { Tinggi } \\
=7\end{array}$ & $\begin{array}{l}\text { tanpa } \\
\text { cacat }\end{array}$ & - & \\
\hline 2 & $\begin{array}{l}\text { Benda padat uji } \\
\text { II }\end{array}$ & $\begin{array}{l}\text { Diameter } \\
=14 \\
\text { Tinggi } \\
=7\end{array}$ & Silinder & $\begin{array}{l}\text { diameter } \\
\text { keacatan }=8 \\
\mathrm{~cm}, \text { tinggi }=7 \\
\mathrm{~cm}\end{array}$ & \\
\hline 3 & $\begin{array}{l}\text { Benda padat uji } \\
\text { III }\end{array}$ & $\begin{array}{l}\text { Diameter } \\
=14 \\
\text { Tinggi } \\
=7\end{array}$ & Kubus & $\begin{array}{l}\text { panjang, lebar, } \\
\text { tinggi kecacatan } \\
=7 \mathrm{~cm}\end{array}$ & \\
\hline
\end{tabular}

IJEIS Vol. 6, No. 1, April 2016 : $69-80$ 


\subsection{Implementasi Sistem}

Implementasi perangkat keras pada penelitian ini terdiri dari implementasi sistem, sensor ultrasonik (sebagai transmitter dan receiver) dan penguat operasional LM386 dan LMC6032. Sistem terhubung dengan AFG sebagai masukan dan oscilloscope sebagai pembaca keluaran sistem. Implementasi dari sistem dimana terdapat yang digunakan sebagai sistem deteksi bentuk kecacatan menggunakan gelombang ultrasonik ditunjukkan pada Gambar 6 .

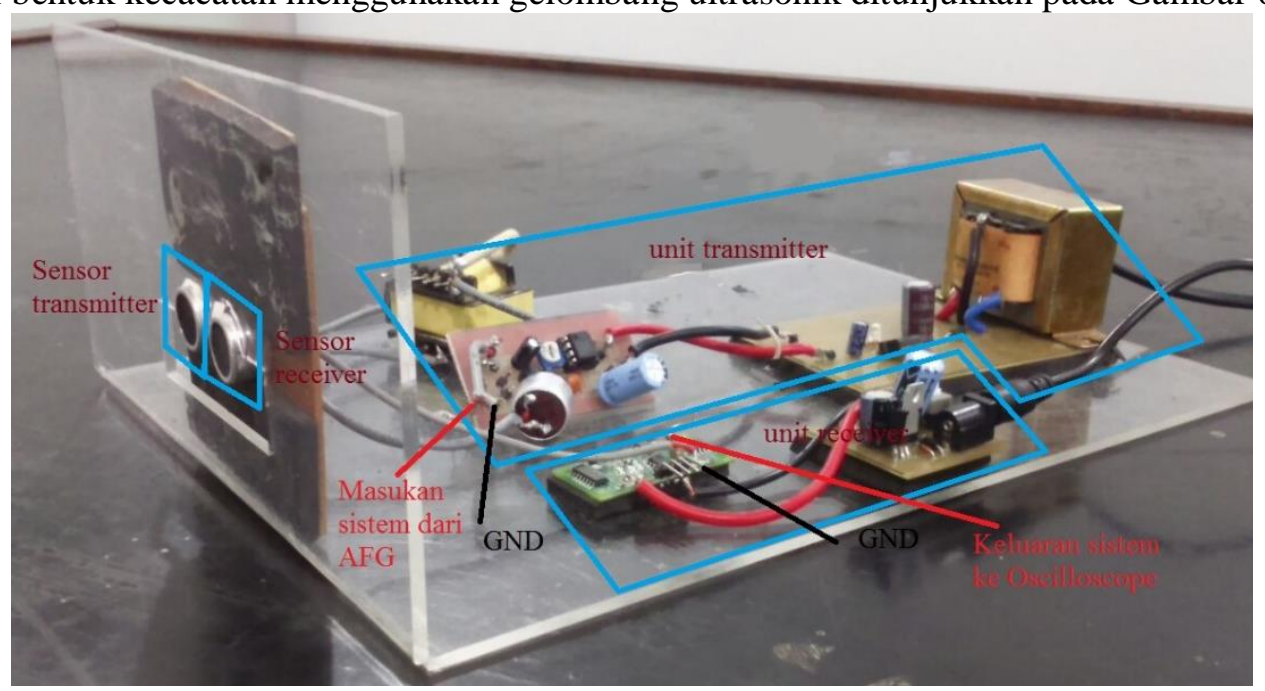

Gambar 6 Implementasi sistem

Gelombang ultrasonik dihasilkan dari AFG yang dihubungkan dengan penguat LM386. Rangkaian penguat operasional LM386 diberi sumber listrik dari catu daya 12 V. Keluaran rangkaian LM386 dihubungkan ke trafo step up yang kemudian baru terhubung ke sensor ultrasonik. Pemasangan sensor ultrasonik sebagai transmitter dan receiver berada pada posisi bersebelahan karena pada penelitian ini menggunakan metode pantul. Gelombang yang dihasilkan oleh unit transmitter akan memantul dan diterima sensor ultrasonik receiver. Sensor tersebut keluarannya dihubungkan dengan penguat LMC6032 pada SRF04. Penguat LMC6032 pada SRF04 diberi sumber listrik dari catu daya 5 V. Sementara itu, gelombang yang dihasilkan berasal dari keluaran penguat LMC6032 dan dibaca atau ditampilkan menggunakan oscilloscope digital.

\section{HASIL DAN PEMBAHASAN}

\subsection{Pengujian Unit Transmitter}

Pengujian gelombang ultrasonik hasil keluaran dari transmitter menghasilkan suatu gelombang yang dapat menembus medium benda padat. Gelombang ultrasonik yang dihasilkan AFG kemudian dikuatkan daya gelombangnya oleh LM386. Selanjutnya dari LM386, keluarannya dinaikkan tegangannya menggunakan trafo step up dengan perbandingan jumlah lilitan 1:20. Dari pengukuran pada kaki sensor transmitter didapat gelombang keluaran yang dihasilkan oleh trafo sebesar $88 \mathrm{~V}$.

Selanjutnya pada unit transmitter ini dilakukan pengukuran amplitudo awal. Amplitudo awal diukur dari hasil keluaran receiver. Sensor ultrasonik receiver ditempel ke sensor ultrasonik bagian receiver untuk mendapatkan suatu gelombang yang terukur tanpa melalui medium perambatan dengan jarak antara transmitter dan receiver dianggap nol. Setelah dilakukan pengukuran, sensor ultrasonik pada transmitter mempunyai amplitudo dengan tegangan sebesar $16 \mathrm{~V}$. Amplitudo awal diukur pada suatu keadaan dimana kedua sensor saling menempel atau tanpa adanya medium perambatan, sehingga besar tegangan sebesar $16 \mathrm{~V}$ merupakan besar gelombang ultrasonik yang tidak teratenuasi. Hal tersebut ditunjukkan pada Gambar 7. 


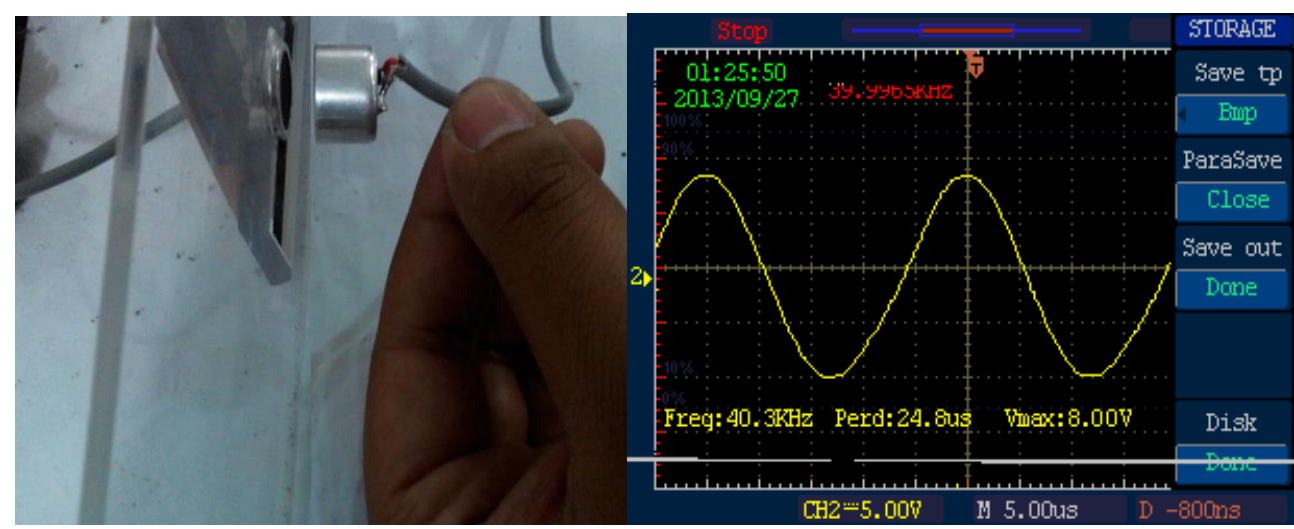

Gambar 7 Pengukuran amplitudo awal unit transmitter

\subsection{Pengujian Unit Receiver}

Pengukuran tegangan gelombang yang dibaca oleh receiver pada kaki sensor ultrasonuk adalah sebesar 4,00 mV. Hal tersebut mengharuskan untuk menambahkan penguat tegangan agar gelombang yang diperoleh mempunyai amplitude yang lebih besar. Selain itu gelombang yang didapat lebih mudah dalam proses pembacaan atau analisis. Seperti yang terdapat pada rancangan sistem pada penelitian ini di bagian unit receiver digunakan penguat LMC6032. Alasan dari pemakaian penguat LMC6032 karena penguat tersebut digunakan dalam receiver SRF04 sehingga pada penelitian ini penguat tersebut dapat langsung digunakan. Hasil gelombang pantul yang telah dikuatkan oleh LMC6032 ditunjukkan pada Gambar 8.

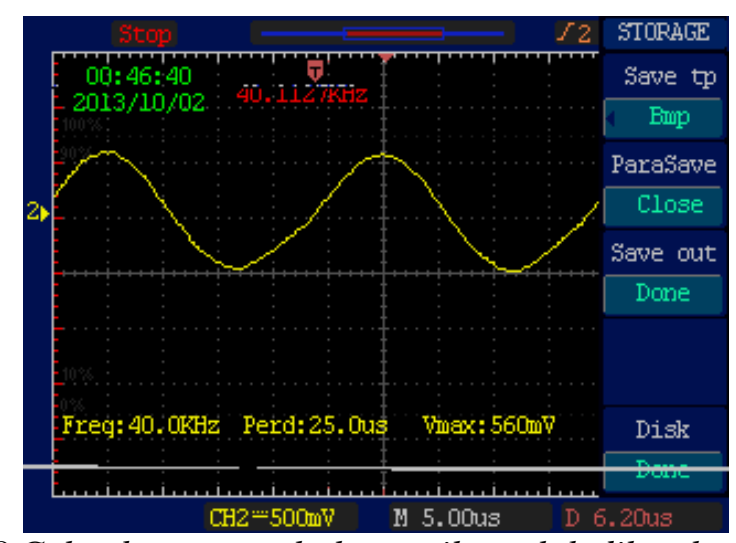

Gambar 8 Gelombang pantul ultrasonik setelah dikuatkan LMC6032

Dengan penguatan yang dilakukan menggunakan penguat LMC 6032 gelombang yang dihasilkan mempunyai besar amplitudo yang lebih besar dibandingkan sebelum dikuatkan. Gelombang yang didapat berupa sinus dan mempunyai frekuensi sebesar $40 \mathrm{KHz}$. Hasil gelombang pantul yang diterima oleh receiver tersebut adalah sebesar 1,02 V. Besar penguatan daya gelombang pantul yang terjadi dapat dilihat pada perhitungan berikut.

$$
\frac{1,12 \mathrm{~V}}{0,004 \mathrm{~V}}=280 \mathrm{kali}
$$

Dari perhitungan dapat dilihat bahwa peguatan yang terjadi setelah melalui LM386 ada lah sebesar 280 kali lebih besar daripada nilai masukannya.

\subsection{Pengujian Benda Padat}

Tabel 2 merupakan perbandingan hasil gelombang setelah sistem diuji pada semua benda padat uji. Gelombang yang dihasilkan pada setiap pengujian mempunyai bentuk yang sama yaitu berbentuk sinusoida. Hal tersebut dapat terjadi karena gelombang masukan yang dibangkitkan oleh AFG berbentuk sinusoida. Sementara itu periode gelombang setiap pengujian

IJEIS Vol. 6, No. 1, April 2016 : $69-80$ 
sebesar \pm 25 us sehingga dapat diketahui bahwa frekuensi yang diterima oleh receiver berada pada nilai 1/25us yaitu $40 \mathrm{KHz}$ yang sesuai dengan frekuensi kerja sensor.

\section{Tabel 2 Hasil pengujian benda padat}

\begin{tabular}{|c|c|c|c|c|}
\hline No & Gelombang keluaran & Keterangan & Tegangan & Atenuasi \\
\hline 1. & 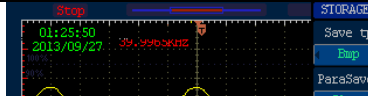 & $\begin{array}{l}\text { Gelombang } \\
\text { mula-mula }\end{array}$ & 16 Volt & $0 \mathrm{~dB}$ \\
\hline 2. & 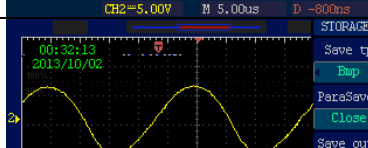 & $\begin{array}{l}\text { Gelombang } \\
\text { pantul benda } \\
\text { padat I }\end{array}$ & 1,15 Volt & $\begin{array}{l}20 \log (16 / 1,15)= \\
22,8 \mathrm{~dB}\end{array}$ \\
\hline 3. & 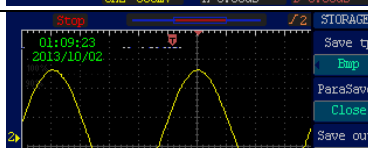 & $\begin{array}{l}\text { Gelombang } \\
\text { pantul benda } \\
\text { padat II }\end{array}$ & 2,35 Volt & $\begin{array}{l}20 \log (16 / 2,35)= \\
16,6 \mathrm{~dB}\end{array}$ \\
\hline 4. & 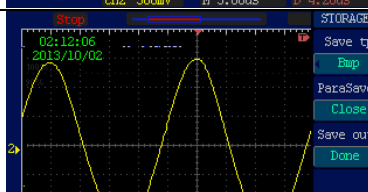 & $\begin{array}{l}\text { Gelombang } \\
\text { pantul benda } \\
\text { padat III } \\
\text { golongan } 1\end{array}$ & 3,105 Volt & $\begin{array}{l}20 \log (16 / 1,15)= \\
14,2 \mathrm{~dB}\end{array}$ \\
\hline 5. & 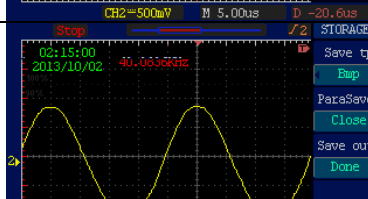 & $\begin{array}{l}\text { Gelombang } \\
\text { pantul benda } \\
\text { padat III } \\
\text { golongan } 2\end{array}$ & 1,93 Volt & $\begin{array}{l}20 \log (16 / 1,93)= \\
18.4 \mathrm{~dB}\end{array}$ \\
\hline
\end{tabular}

\subsubsection{Pengujian benda padat pertama}

Gambar 9 merupakan perbandingan dari bentuk benda padat hasil dari deteksi sistem dan bentuk benda padat yang sebenarnya. Gambar 9 A merupakan hasil deteksi pada benda padat uji yang pertama yang digambarkan berdasarkan grafik hubungan tegangan dengan variasi sudut sensor. Pada benda padat uji yang pertama ini mempunyai besar tegangan yang relatif sama sehingga dapat dipastikan gelombang ultrasonik merambat pada jarak tempuh yang relatif sama pula pada setiap variasi sudut. Gambar 9 B merupakan benda padat uji yang sebenarnya yang berbentuk silinder utuh dengan diameter $14 \mathrm{~cm}$. Hasil deteksi pada benda padat yang pertama ini adalah gelombang ultasonik memantul pada sisi balik dari sudut uji atau dapat dikatakan sebagai benda padat yang utuh tanpa adanya kecacatan di dalamnya. 


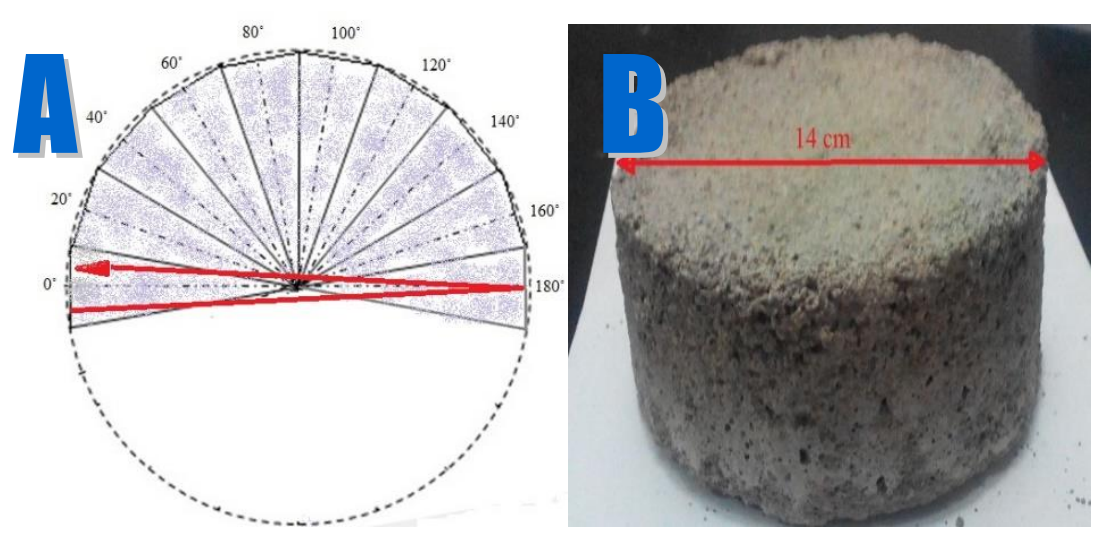

Gambar 9 Pola kecacatan benda padat uji pertama

\subsubsection{Pengujian benda padat kedua}

Gambar 10 adalah bentuk dari kecacatan benda padat yang dideteksi dan bentuk dari kecacatan benda padat kedua yang sebenarnya. Pada Gambar 10 A merupakan gabungan dari setiap area variasi sudut yang dideteksi. Hasil pantulan yang relatif sama dan rambatan gelombang yang tidak mencapai sisi balik dari sisi uji menunjukkan adanya perbedaan medium di tengah benda padat tersebut dengan jarak tempuh gelombang yang relatif sama pada setiap variasi sudut yang diuji. Oleh karena itu, pada deteksi benda padat yang kedua ini dihasilkan suatu bentuk kecacatan benda padat yang berbentuk lingkaran apabila tampak dari atas. Gambar 10 B merupakan bentuk dari benda padat yang sebenarnya. Diameter dari benda padat uji adalah $14 \mathrm{~cm}$ sementara itu diameter dari lubang di tengah benda padat adalah $8 \mathrm{~cm}$. Selisihnya merupakan jarak dari sisi selimut benda padat uji ke lubang yang ada di tengah benda padat rata-rata sebesar $3 \mathrm{~cm}$. Dengan jarak tempuh sebesar $3 \mathrm{~cm}$, gelombang ultrasonik dengan tegangan mula mula $16 \mathrm{~V}$ memantul kembali dan diterima receiver hanya menyisakan gelombang dengan amplitudo sebesar 4,7 div atau 2,35 V. Dari perhitungan pelemahan daya dari gelombang dapat diketahui bahwa pada benda padat uji ini gelombang yang teratenuasi $16,6 \mathrm{~dB}$ terjadi pada jarak tempuh gelombang sepanjang $3 \mathrm{~cm}$.

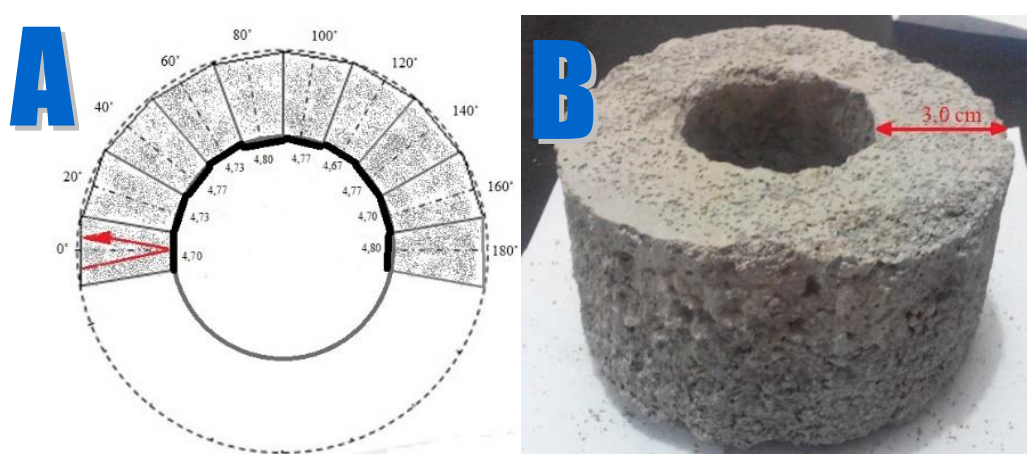

Gambar 10 Pola kecacatan benda padat uji kedua

\subsubsection{Pengujian benda padat keetiga}

Gambar 11 merupakan perbedaan bentuk kecacatan hasil deteksi sistem dan bentuk kecacatan dari benda padat uji yang sebenarnya. Pada Gambar 11 A rambatan gelombang ultrasonik yang terjadi pada setiap area varian sudut digabungkan. Setiap variasi pengujian didapat dua nilai tegangan gelombang yang berbeda. Hal tersebut dapat terjadi akibat adanya perbedaan jarak tempuh gelombang ultrasonik yang merambat. Amplitudo yang kecil menunjukkan jarak kecacatan yang besar, sementara itu amplitudo yang lebih besar menunjukkan jarak kecacatan yang lebih kecil. Titik merah pada Gambar 11 A ada pada setiap area varian sudut yang menunjukkan salah satu titik dari medium yang membuat gelombang

IJEIS Vol. 6, No. 1, April 2016 : $69-80$ 
memantul. Dari setiap titik pada setiap variasi sudut kemudian ditarik garis yang melewati setiap titik. Dari pola garis tersebut tersebut tampak suatu bentuk kecacatan yang terdeteksi oleh sistem. Bentuk yang ditunjukkan masih berbentuk suatu segi yang kasar. Hal tersebut diakibatkan oleh keterbatasan varaisi sudut yang dilakukan setiap $20^{\circ}$. Keterbatasan dari variasi sudut tersebut mengakibatkan setiap variasi sudut masih memiliki area yang besar dan menjadikan pola yang dibentuk masih kasar.

Terlepas dari kekasaran pola yang didapat, dari pola yang terdeteksi terdapat adanya perbedaan garis hubung atau medium pantul yang cukup menonjol yaitu sudut $20^{\circ} \mathrm{ke} 40^{\circ}, 60^{\circ}$ ke $80^{\circ}$ dan $120^{\circ}$ ke $140^{\circ}$ ke $160^{\circ}$. Perbedaan tersebut dapat dijelaskan pada Gambar $11 \mathrm{~B}$ yang merupakan bentuk kecacatan benda padat uji yang sebenarnya dimana antara sudut $40^{\circ}$ dengan $60^{\circ}$ terdapat sudut siku dari kecacatan benda padat. Sementara itu pada area sudut $140^{\circ}$ terdapat sudut siku lainnya dari kecacatan benda yang berada tepat di dalam area.

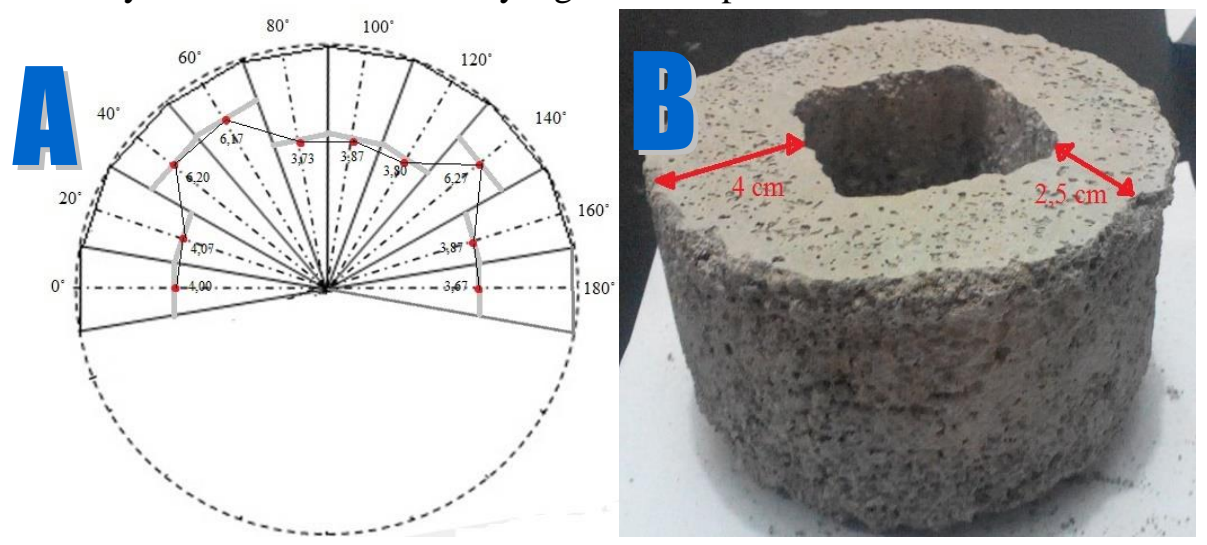

Gambar 11 Pola kecacatan benda padat uji ketiga

\section{KESIMPULAN}

Dari hasil pengamatan, pengujian dan analisis dari hasil yang diperoleh, kesimpulan sebagai berikut :

1. Sistem deteksi bentuk kecacatan pada benda padat dengan teknik variasi sudut ultrasonik telah berhasil dibuat.

2. Unit transmitter mampu menghasilkan gelombang ultrasonik berbentuk sinus dengan frekuensi sebesar $\pm 40 \mathrm{KHz}$.

3. Unit receiver mampu menerima gelombang ultrasonik hasil pantulan dari transmitter ke benda padat uji yang dibaca menggunakan oscilloscope.

4. Metode variasi sudut dengan memutar benda padat uji setiap kelipatan $20^{\circ}$ pada 0 $180^{\circ}$ sisi selimutnya dapat menentukan bentuk dari kecacatan benda padat uji. Bentuk yang dideteksi berupa benda padat uji tanpa kecacatan, benda padat uji dengan kecacatan berbentuk silinder dan benda padat uji dengan kecacatan berbentuk kubus.

\section{SARAN}

Penelitian lebih lanjut diharapkan dapat memperbaiki kekurangan yang ada dan diharapkan dapat mengembangkan apa yang telah dilakukan pada penelitian ini. Untuk itu disarankan hal-hal berikut :

1. Sensor yang digunakan untuk deteksi kecacatan didalam benda padat berupa sensor ultrasonik tunggal sehingga dimensi sensor akan lebih kecil dan variasi sudut yang dilakukan semakin kecil. 
2. Gelombang ultrasonik yang dibangkitkan oleh transmitter berupa gelombang diskrit sehingga gelombang yang didapat berupa grafik dengan domain waktu untuk menghitung kedalaman cacat secara otomatis.

3. Dari hasil penelitian ini sudah dapat mendeteksi bentuk dari kecacatan benda padat yang terbuat dari semen, pasir dan air tetapi sistem ini tidak bisa mendeteksi benda padat yang terbuat dari material logam karena terbatas pada frekuensi kerja sensor sehingga perlu dilakukan penelitian lebih lanjut salah satunya dengan menggunakan sensor ultrasonik dengan frekuensi kerja lebih tinggi.

\section{UCAPAN TERIMA KASIH}

Penulis mengucapkan terima kasih kepada bapak Abdul Rouf dan bapak Tri Wahyu Supardi selaku dosen pembimbing Tugas Akhir yang sudah bersedia meminjamkan sensor untuk penelitian ini. Tak lupa juga penulis mengucapkan terima kasih teman - teman Elins 2010 serta kepada pihak-pihak terkait yang telah membantu dalam penelitian ini.

\section{DAFTAR PUSTAKA}

[1] Charles, H.,2003, Handbook of Non Destructive Evaluation, USA: Mcgraw-Hill Companies.

[2] Subiyanto, L. dan Sardjono, T., 2012, Deteksi Cacat Pada Material Baja Menggunakan Ultrasonik Non-Destructive Testing Dengan Metode Continuous Wavelet Transform, Seminar Nasional Teknologi Informasi Komunikasi Terapan, ITS, Surabaya.

[3] Ludwig, R. dan Roberti, D., 1989, A Nondestructive Ultrasonik Imaging Sistem for Detection of Flaws in Metal Blocks, IEEE Transactions On Instrumentation and Measurement Vol. 38 No. 1, Worcester.

[4] Sung, J., Furgason, E. dan Shin, Y., 1994, Surface Roughness Evaluation Via Ultrasonik Scanning, IEEE Transactions On Ultrasoniks, Ferroelectrics and Frequency Control Vol. 41 No. 6, West Lafayette, USA. 